\title{
Cardiologic evaluation of children with suspected heart disease: experience of a public outpatient clinic in Brazil
}

Pediatric Cardiology Outpatient Clinic, SUS and Department of Pediatrics, Faculdade de Medicina de Ribeirão Preto, Ribeirão Preto, Brazil

\section{SUMMARY}

Context: During initial evaluation of children on an outpatient basis, the index of suspected heart disease may be high, particularly if we consider that innocent murmur occurs in about $50 \%$ of the pediatric population. This is the most common cause of referral to the pediatric cardiologist. Objective: To report on the experience of a public outpatient clinic in the southeastern region of Brazil. Design: Retrospective analysis of all patients submitted to cardiologic evaluation within a 39 month period.

Setting: public pediatric cardiology outpatient clinic. Participants: 2675 consecutive children aged $\leq 15$ years referred from the local and regional basic health units due to suspected heart disease.

Main Measurements: Reason for referral, diagnostic investigation, final diagnostis based on the reason for referral, therapeutic procedures.

Results: The main reasons for referral were: murmur $(70 \%)$, precordial pain ( $9 \%)$, suspicion of arrhythmia (9\%) and breathlessness (5\%). Of the total number, 695 cases $(26 \%)$ did not complete the investigation and were not included in the analysis. A final diagnosis was obtained based on the reason for referral and the main conclusions were: I) a high incidence of normality was found: murmur $(83 \%)$, pain $(98 \%)$, arrhythmia $(97 \%)$ and breathless $(94 \%) ; 2$ ) heart disease was unlikely, based on other referral reasons; 3 ) $14 \%$ of the children were considered abnormal and $1 \%$ needed therapeutical procedures. Condusions: The establishment of a pediatric cardiology outpatient clinic within the public health service in the region seems to be justifiable, due to the high current demand. The low global incidence of heart disease, with a high prevalence of children with innocent murmur, discloses the need for a specific training program in cardiology for pediatricians. Key words: Heart disease. Child. Incidence. Epidemiology.
INTRODUCTION

During initial evaluation of children on an outpatient basis, the index of suspected heart disease may be high, particularly if we consider that innocent murmur occurs in about $50 \%$ of the pediatric population. ${ }^{1-3}$ This is the most common cause of referral to the pediatric cardiologist, with several reports of such experience published worldwide. 0 ther causes like chest pain, breathlessness at rest and on effort and arrhythmia are less frequent, although not less important in this setting. 0 bviously, the decision to refer a patient for a specialist consultation is mainly dependent on the ability of the pediatrician to recognize heart disea se. This inherent characteristic is certainly related to the information provided during graduate and post-graduate training, which seems to vary from country to country, and is also related to individual skill.

The purpose of this paper is to present experience from a public outpatient clinic for pediatric cardiology situated in the state of São Paulo, in the southeast of Brazil. The results are based on a prospective study of 2675 consecutive children under the age of 15 , all of them referred from pediatricians for a cardiac evaluation. 
METHODS

The great majority of the 2675 cases were referred from the 32 so-called Basic Health Units (BHU) located in the city of Ribeirão Preto, state of São Paulo, Brazil, where primary pediatric care is offered daily. The material was collected from September 1990 to December 1993 (a period of 39 months). The male sex was predominant: 1444 cases (54\%). Regarding the age at referral, 26 patients (1\%) were neonates, $455(17 \%)$ were infants, 830 (31\%) were of preschool age and 1364 (51\%) were children of school age.

Every patient was seen in an adequate and silent room in the outpatient clinic, with history and physical examination directed towards the cardiovascular system. Based on the data from the clinical examination alone, an initial diagnosis was made and all the patients were submitted to an electrocardiogram (EKG). 0 ther tests like chest $X$-ray, echocardiogram and hemodynamic studies were only done when heart disease was obvious, the type of test being requested in accordance with the clinical diagnosis. The investigation was completed in $74 \%$ of the cases. To fulfill the criterion of complete investigation, all the patients would have to return to the clinic either with only the EKG (in cases considered normal when first seen) or with EKG plus other tests for those with heart disease diagnosed solely on clinical grounds. A fter the final diagnosis was established (clinical plus laboratory test data), management was determined according to the specific problem. All the clinical and laboratory data has been stored in the computer section of the Pediatrics department (Figure 1).

\section{RESULTS}

\section{1) Reason for referral}

The most frequent cause of referral was the presence of a heart murmur: 1872 patients $(70 \%) .0$ ther reasons were: chest pain, mainly in the precordial region: 240 (9\%); suspicion of arrhythmia: 240 (9\%); and breathlessness at rest and/ or on effort: 134 (5\%). These four reasons for referral accounted for $93 \%$ of the cases on first examination. 0 ther less frequent causes of referral were: cyanosis: $40(1.5 \%)$; cardiomegaly on the chest X-ray: $26(1 \%)$; history of rheumatic fever: $21(0.8 \%)$; splitted second sound (S2): $21(0.8 \%)$; and systemic hypertension: $19(0.7 \%)$. These cases, added to the most frequent causes described earlier, comprised $97.8 \%$ of the cases studied. The other $2.2 \%$ included a very varied spectrum of causes: unknown $(n=8)$, syncope $(n=8)$, presence of a third heart sound (S3) $(n=7)$, diagnostic opinion $(n=7)$, need for surgical follow -up $(n=5)$, splitted first heart sound (S1) $(n=4)$, dizziness $(n=3)$, increased S2 $(n=2)$, Down's syndrome $(n=2)$, fa milial heart disease $(n=2)$, heart failure $(n=2)$, chest deformity $(n=2)$, red spots on the skin $(n=2)$, past history of endocarditis $(n=2)$, systemic hypotension $(n=2)$, increased S1 $(n=2)$, leg edema $(n=1)$ and religious recommendation $(n=1)$.

\section{2) Diagnostic investigation}

A mong the 2675 firstexamined patients, $695(26 \%)$ did not complete the investigation according to the preestablished criteria and were not included in the analysis of the results. There was little difference in the incidence of patients who did not complete the investigation, in relation to the main reasons for referral: murmur $(26 \%)$, chest pain (24\%), breathlessness (25\%) and arrhythmia (21\%).

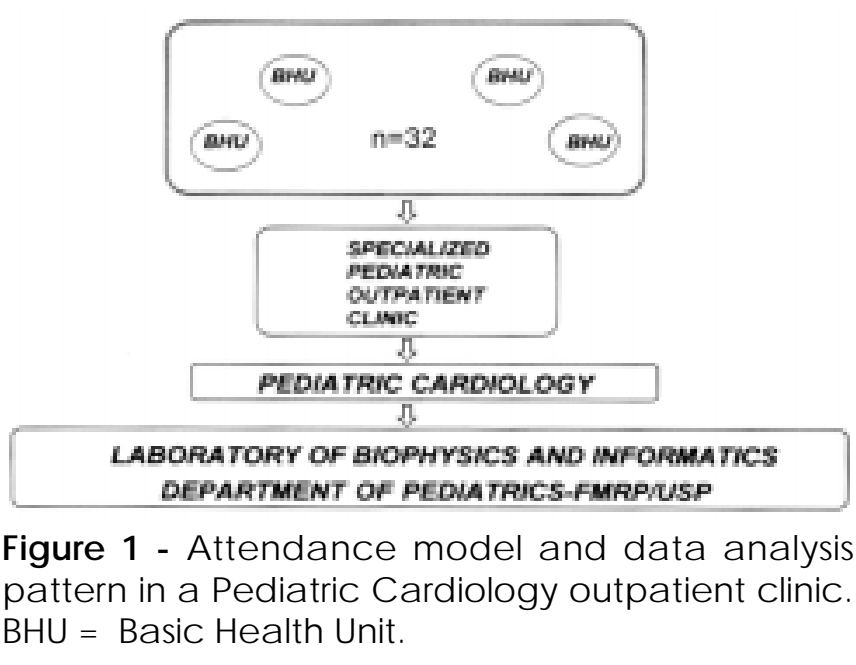




\section{3) Final diagnosis based on the reason for referral}

Heart murmur: in 1271 cases the murmur was confirmed. A mong these, 1042 (82\%) were considered innocent. Regarding the 229 (18\%) pathologic murmurs, the most frequently found diseases were: ventricular septal defect (VSD): 82 (38\%); pulmonary valve stenosis (PVS): 41 $(19 \%)$; aortic valve stenosis (AVS): 24 (11\%); atrial septal defect (ASD): $13(6 \%)$; and mitral regurgitation (MR): $10(5 \%)$. The other $21 \%$ of patients corresponded to various forms of heart disease: mitral valve prolapse (MVP) $(n=9)$, persistent ductus arteriosus (PDA) $(n=7)$, tricuspid valve insufficiency $(n=5)$, idiopathic dilatation of the main pulmonary artery $(n=5)$, atrioventricular septal defect (AVSD) $(n=4)$, dilated cardiomyopathy $(n=3)$, transposition of the great arteries $(n=3)$, pulmonary valve regurgitation $(n=2)$, short PR interval on the EKG $(n=2)$, myocarditis $(n=2)$, tricuspid a tresia $(n=2)$, false tendon of the left ventricle $(n=1)$, a ortic regurgitation due to a bicuspid a ortic valve $(n=1)$, primary pulmonary hypertension $(n=1)$ and long Q T syndrome $(n=1)$.

Chest pain: in 190 cases studied, 186 $(98 \%)$ were considered normal from the cardiac point of view. In 4 patients, signs of possible heart disease were found: idiopathic dilatation of the main pulmonary artery $(n=2)$, mild $M R$ and short PR interval on the EKG.

A rrhythmia: among the 195 cases referred, 187 (96\%) were considered normal, while 8 cases presented pathologic features: WolfParkinson-W hite syndrome $(n=2)$, symptomatic sinus bradycardia, documented supraventricular tachycardia, frequent ventricular ecto pics, ASD, PVS and short PR interval.

Breathlessness: in 100 cases studied, 93 (93\%) were normal and in 7 , evidence of heart disease was found: complete rightbundle branch blockage $(n=2), A S D$, short PR interval, primary pulmonary hypertension, AVSD and idiopathic dilatation of the main pulmonary artery.

Cyanosis: 40 cases were referred because of this signal, all of whom were normal.

A bnormal chest $X$-ray: a mong the 24 cases referred, 19 (79\%) were normal, while 5 were considered abnormal: dilated cardiomyopathy $(n=2)$, idiopathic dilatation of the main pulmonary artery $(n=2)$ and mild mitral regurgitation.

Splitted second heartsound: in the 21 cases referred because of this possible abnormal finding, $19(90 \%)$ were normal while in 2, complete right bundle branch blockage was documented.

Systemic hypertension: a mong the 19 cases referred, 10 (55\%) had normal blood pressure, while in $9(45 \%)$ hypertension was documented.

Regarding the 62 patients referred due to a variety of reasons such as: history of rheumatic fever, edema, heartfailure, systemic hypotension, diagnostic opinion, increased $S 1$, syncope, splitted S1, chest deformity, post-operative followup, unknown cause, red spots, increased S2, dizziness, religious recommendation, history of endocarditis, familial heart disease and Down's syndrome, $54(87 \%)$ were normal while in 8 (13\%) a cardiovascular abnormality was found: PVS $(n=2)$, VSD $(n=2)$, rheumatic MR, W PW syndrome, residual post-operative pulmonary stenosis and residual post-operative aortic regurgitation.

\section{4) Therapeutic procedures}

Seventeen patients (1\%) were referred to a tertiary unit for specific treatment after the final diagnosis was established. Three cases were submitted to therapeutic catheterization: 2 pulmonary valvo plasty and 1 PDA occlusion with a Sideris prosthesis (4). Fourteen cases were operated on: ductus ligation $(n=5)$, relief of coarctation of the a orta $(n=2)$, closure of an ASD

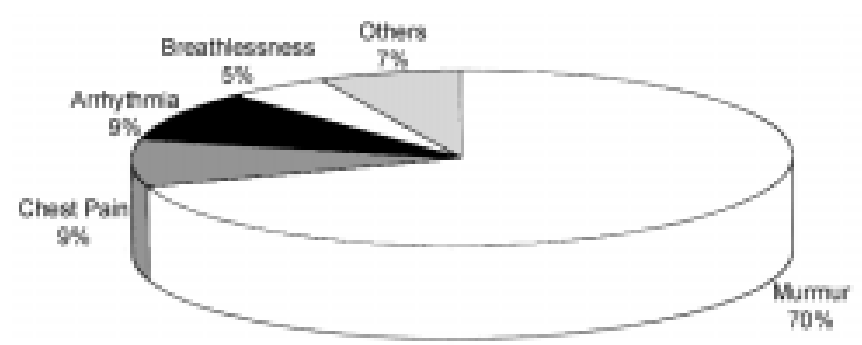

Figure 2 - Referral rea sons in 2675 child ren submitted to cardiologic evaluation. 
$(n=2)$, closure of a VSD $(n=2)$, correction of an $\operatorname{AVSD}(n=2)$ and relief of suba ortic stenosis $(n=1)$.

\section{DISCUSSION}

The a nalysis of our data shows that, at first, the index of suspected heart disease is high during the initial pediatric evaluation. The 2675 consecutive cases here presented were collected during a 39 -month period, corresponding to approximately 68 patients/month, which should be considered a significant number for a subspeciality. Regarding this epidemiological detail, it should be noted that referral to our clinic is not compulsory, and it is likely that other cases have been referred to other centers, characterizing the possibility of choice during the referral process. Another point which we believe should be emphasized is that $26 \%$ of the 2675 patients initially evaluated did not complete the investigation. This is a matter for concern but, unfortunately, difficult to clarify. However, it is important from an epidemiological point of view that this number should be reduced, considering factors such as the characteristics of the place where patients are seen, doctor-patient relationships and also individual problems.

It is well known that the majority of patient referrals to pediatric cardiology clinics are due to heart murmurs. As is well-confirmed in the litera ture, ${ }^{1-3}$ the innocent murmur, which accounts for a great number of these referrals, occurs in aproximately $50 \%$ of the normal pediatric population. Although the origin of these murmurs is not well defined, its association with intraventricular fibromuscular bands ${ }^{5}$ is widely known, especially the musical Still murmur. ${ }^{6}$ These bands, however, are considered normal variations and no cause-effect relationship ${ }_{7}$ with the murmur has been demonstrated so far.

0 ur data confirm this information: $70 \%$ of the cases referred to our clinic were due to a heart murmur. The final analysis revealed that the great majority of these cases (82\%) were innocent murmurs, meaning absence of heart disease. This data, in a greement with information from the literature, ${ }^{8}$ makes us consider two initial hypotheses: either there is a high degree of concern aboutheart disease in the region or there is a lack of specific knowledge which would allow the pediatrician to recognize an innocent murmur. As this diagnosis can be made on strictly clinical grounds, ${ }^{9-11}$ with a low probability of error, we may conclude that in the great majority of our patients, heart disease could have been ruled out at the first pediatric examination.

It should be remembered, how ever, that the diagnosis of an innocent murmur may be very subjective and influenced by many factors, like an adequate environment, the organic and emotional state of the child and the experience of the investigator. Doubts may arise in some circumstances, with some authors using the term 'possibly pathologic' to describe a murmur. ${ }^{12} \mathrm{We}$ believe these cases should be sent to a pediatric cardiology examination. A mong the 229 (18\%) cases of pathologic murmurs in our material, we noticed that the majority of them corresponded to causes usua lly detected in day-to-day pediatric cardiology practice: VSD, PVS, AVSD, ASD and $M R$. M ost of these cases were considered mild forms of the diseases, with no treatment being required. However, careful follow-up is recommended for these patients. Specific details like long term prognosis of the disease, physical activity, life insurance, working capacity, pregnancy and prophylaxis against bacterial endocarditis require adequate counseling, depending on the type of heart disease present.

The second most frequent cause of referral

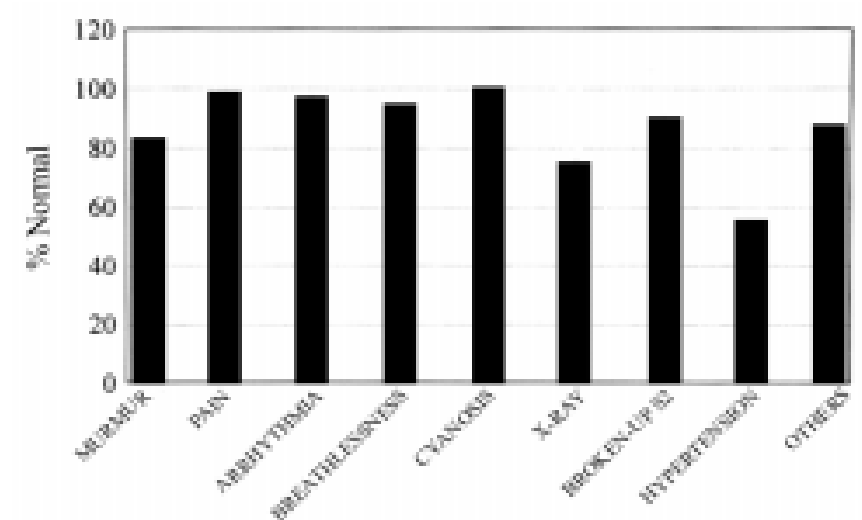

Figure 3 - Inc idence of ca rdiova sc ula r no ma lity related to the referral reasons in 2675 children with suspected heart disease. 
$(9 \%)$ in our material was chest pain. A mong the 190 cases studied, 186 (98\%) were normal. The 4 abnormal cases were: mild mitral regurgitation $(n=2)$, idiopathic dilatation of the main pulmonary artery and shortPR interval, and were incidental findings, not related to the pain itself. This symptom is very common in general medical practice and quite relevant due to the significant incidence of hypertensive and atherosclerotic disease in society. ${ }^{13,14}$ The identification of organic disease is not common in this situation, although some forms of heart disease may provoke precordial pain: severe aortic stenosis, mitral valve prolapse, ${ }_{15}^{16}$ hypertrophic cardiomyopathy, ${ }^{15}$ coronary artery anomaly, pericarditis, ${ }^{17}$ Kawasaki disease ${ }^{18}$ and arrhythmia. ${ }^{13}$ All these possibilities were ruled out in our cases due to the absence of compatible clinical findings. A lso, the EKG was normal but, nevertheless, we believe it should be recorded in any patient with precordial pain. 0 ur current policy is to send the patient back to the pediatrician for further investigation, if necessary.

Suspected a rrhythmia was a nother frequent reason for referral (9\%) among our material. These children either presented symptoms like palpitations or had arrhythmia noticed by the mother and/ or pediatrician, usually as an irregular rhythm. In the 195 cases studied, 187 $(96 \%)$ were normal, the great majority of them with sinus arrhythmia on the EKG, a frequent and benign finding in normal children. ${ }^{19}$ Eight cases were considered abnormal: ventricular ectopics requiring medical treatment $(n=3)$; W PW syndrome incidentally found on the EKG without documented a rrhythmia $(n=2)$; supraventricular tachycardia $(n=2)$; and symptomatic sinus bradycardia $(n=1)$. Characterizing an abnormal rhythm only by auscultation may be difficult, especially if an irritable child is being examined. The rhythm irregularity is usually audible and very often caused by a sinus arrhythmia, but despite this, we believe the EKG should always be recorded in order to rule out rhythm abnormality.

The complaint of breathlessness at rest and/ or on effort was present in $5 \%$ of our cases and, out of the 100 cases analyzed, 93 (93\%) were normal. In 7 abnormal cases the diagnoses were: atrial septal defect, primary pulmonary hypertension, atrioventricular septal defect, complete right bundle branch blockage $(n=2)$, short PR interval and idiopathic dilatation of the main pulmonay artery. It should be noted that only the first 3 cases could possibly have some relation with the main symptom.

Cyanosis ocurred in $1.5 \%$ of our cases as the main complaint. It is interesting to note that all the patients were considered normal after investigation. It is well-known that parents erroneously associate the purple lips of a crying child with heart disease, at least in our culture.

Heart disease suspected exclusively as a result of chest X-ray ocurred in $1 \%$ of our patients. In the 24 cases investigated, 19 were normal while 5 were labeled as pathological: dilated cardiomyopathy $(n=2)$, mitral regurgitation $(n=1)$ and idiopathic dilatation of the main pulmonary artery $(n=2)$. The first 3 cases had to be followed up. Pulmonary artery dilatation, a common finding in daily practice, is usually considered a benign abnormality, despite a recently reported serious complication $^{20}$ in one such case. Care must be taken when interpreting a chest $X$-ray: inadequate technique may be responsible for apparentabnormalities on the film. Total absence of clinical and/or electrocardiographic correlation allowed us to consider cases as being normal.

An interesting semiologic mistake was detected in our patients: 21 cases were referred because of a broken-up second heart sound. $\mathrm{N}$ ineteen of them were normal and we may conclude the physiologic split was not recognized. In 2 cases a complete right bundle branch blockage was recorded, which explains the auscultatory finding.

In the 19 cases referred because of hypertension, 10 (55\%) were normal, and probably an inadequate cuff size had been used. A mong the 9 cases with hypertension, 2 had coarctation of the a orta.

The remaining $2.2 \%$ of our cases were referred because of a wide variety of reasons (see 
Results). Among the 62 cases studied, 54 (87\%) were normal while $8(13 \%)$ had some form of heart disease: pulmonary valve stenosis $(n=2)$, ventricular septal defect $(n=2)$, W PW syndrome, mitral regurgitation, postoperative residual pulmonary stenosis and post-operative residual a ortic stenosis. The very low incidence of each of the reasons for referral among this group of patients makes it impossible to perform a reliable analysis.

The very low index of therapeutic need found in our material $(1 \%)$ reflects the rela tive benignity of patients' complaints referred to the clinic. The 14 cases operated on, as well as the 3 patients submitted to an interventional catheterization, had a form of congenital heart disease frequently classified as "simple", usually with a good prognosis. A nother fact which also characterizes the benign aspect is that the global incidence of heart disease was $14 \%$. For comparison, the experience gained in the pediatric cardiology outpatient clinic of the Heart Hospital located in the same city, where tertiary treatment is routinely offered, should be mentioned. At this institution, during a 12 -month period, 420 patients were evaluated for suspected congenital heart disease. Among them, only $6(1.5 \%)$ cases were considered normal, with a wide spectrum of heart disease being documented (unpublished observations). This pattern of referral is different from the pattern of our material presented above. The great majority of the patients referred to the Heart Hospital had already been seen by a pediatrician and also by a local cardiologist before being sent for specific treatment.

In conclusion, we believe the setting up of a pediatric cardiology outpatient clinic is justifiable in any large program of pediatric primary care. The high demand is mainly due to the inability of the pediatrician to differentiate between normal and abnormal hearts. Despite the low global incidence of heart disease $(14 \%)$, this number becomes relevant in analysis on an individual basis. The great majority of our patients were referred because of a heart murmur, most of them being innocent. The possibility of heart disease related to other referral reasons is remote and invasive thera py is rarely necessary. These data have been routinely compared through the years. Part of this material has been published elsewhere and the results are essentially the same. ${ }^{22}$ It would be interesting to compare these results with those from other centres and different cultures. M ore detailed studies seem to be relevant in order to decrease the high index $(26 \%)$ of patients who do not return to the clinic after the first visit. It seems obvious that a specific training program for pediatricians is highly recommended in order to avoid unnecessary referral.

\section{REFERENCES}

1. Friedman S, Robie WA, Harris TN. Occurrence of innocent adventitious cardiac sounds in childhood. Pediatrics 1949;4:782-9.

2. Gibson S. Clinical significance of heart murmurs in children. Med Clin North Am 1946;30:35-6.

3. Thayer WS. Reflections on the interpretation of systolic cardiac murmurs. Am J Med Sci 1925;169:313-21s.

4. Sideris EB, Sideris SE, Ehly RL. Occlusion of patent ductus arteriosus in piglets by a double-disc self-adjustable device. Abstract. J Am Coll Cardiol 1990;15:240A.

5. Geva T, Hegesh J, Frand M. Reappraisal of the approach to the child with heart murmur: is echocardiography mandatory? Int J Cardiol 1988;19:107-13.

6. Roberts WC. Anomalous left ventricular band: an unemphasized cause of precordial musical murmurs. Am J Cardiol 1969;23:735-8.

7. Schwartz MI, Goldberg SJ, Wilson N, et al. Relation of Still's murmur, small aortic diameters and high aortic velocity. Am J Cardiol 1986;57:1344-8.

8. Caceres CA, Perry LW. The innocent murmur: a problem in clinical practice. Boston: Little Brown and Co; 1967.

9. Newburger JM, Rosenthal A, Williams RG, Fellows K, Miettinen OS. Noninvasive tests in the initial evaluation of heart murmurs in children. N Engl J Med 1983;308:61-4.

10. Tavel ME. The systolic murmur: innocent or guilty? Am J Cardiol 1977;39:757-9.

11. Amaral FTV, Granzotti JA, Nunes MA. Abordagem da criança com sopro cardíaco: importância diagnóstica dos exames complementares não invasivos. Arq Bras Cardiol 1995; 64:195-9.

12. Smythe JF, Teixeira OHP, Vlad P, Demers PP, Feldman W. Initial evaluation of heart murmurs: are laboratory tests necessary? Pediatrics 1990;86:497-500.

13. Brenner JI, Ringel RE, Berman MA. Cardiologic perspectives of chest pain in childhood: a referral problem? to whom? Ped Clin North Am; 1984:1241-58.

14. Epstein SE, Gerber LH, Borer JS. Chest wall syndrome: a common cause of unexplained cardiac pain. J Am Med Assoc 1979;241:2793-7.

15. McKenna W, Deanfield J, Faruqui A, et al. Prognosis in hypertrophic cardiomyopathy: role of age, clinical and hemodynamic features. Am J Cardiol 1981;47:532-8. 
16. Bisset GS, Schwartz DC, Meyer RA, et al. Clinical spectrum and long term follow-up of isolated mitral valve prolapse in 119 children. Circulation 1980;2:423-9.

17. Okoroma EO, Perry LW, Scott LP. Acute bacterial pericarditis in children: report of 25 cases. Am Heart J 1975;90:709-13.

18. Melish ME. Kawasaki syndrome (the mucocutaneous lymph node syndrome). Pediatr Ann 1982;11:255-68.

19. Bertoletti JC. Disritmias cardíacas. In: Cardiologia Pediátrica. Macruz R, Snitcowski R. São Paulo: Sarvier;1983:601.

20. Andrews R, Colloby P, Hubner JB. Pulmonary artery dissection in a patient with idiopathic dilatation of the pulmonary artery: a rare cause of sudden cardiac death. Br Heart J 1993;69:268-9.

21. Gidding SS, Rosenthal $A$. The interface between primary care and Pediatric Cardiology. Ped Clin North Am 1984;31:1367-88.

22. Amaral FTV, Granzotti JA, Nunes MA. Sopro cardíaco na criança: experiência de um ambulatório especializado. Rev Paul Pediatr 1995;13:39-41.
Fernando Amaral - M aster in Cardiology, Division of Pediatric Cardiology, Department of Pediatrics, Faculdade de Medicina de Ribeirão Preto.

João Antonio Granzotti - M D, Assistant Professor, Head-Division Pediatric Cardiology, Department of Pediatrics, Faculdade de Medicina de Ribeirão Preto.

\author{
Sources of Funding: $\mathrm{N}$ ot declared \\ Conflict of interest: $\mathrm{N}$ ot declared \\ Last received: 12 may 1998 \\ Accepted: 1 June 1998 \\ Address for correspondence:
}

Fernando A maral

Av. Independência, 1379

Ribeirão Preto/ SP - Brasil - CEP 14025-390

Contexto: Durante a avaliação inicial de crianças em nível ambulatorial, o índice de suspeita de cardiopatia pode ser elevado, particularmente se for considerado que o sopro inocente ocorre em aproximadamente $50 \%$ da população pediátrica. Esse ruído é a causa mais comum de encaminhamento ao cardiologista pediátrico. Objetivo: Relatar a experiência de um ambulatório de cardiologia pediátrica da rede pública de saúde na região sudeste do Brasil. Tipo de estudo: A nálise retrospectiva de todos os pacientes encaminhados para avaliação cardiológica dentro de um período de 39 meses. Local: A mbula tório de cardiologia pediátrica da rede pública de saúde. Participantes: 2675 crianças consecutivas procedentes das unidades básicas de saúde locais e da região, encaminhadas devido à suspeita de cardiopatia. Variáveis Estudadas: M otivo do encaminhamento, investigação diagnóstica, diagnóstico final baseado no motivo de encaminhamento, procedimentos terapêuticos. Resultados: 0 s principais motivos de encaminhamento foram: sopro cardíaco (70\%), dor precordial (9\%), suspeita de arritmia ( $9 \%$ ) e dispnéia (5\%). Entre o grupo total, $695(26 \%)$ casos não completaram a investigação e não foram incluídos na análise. Foi estabelecido um diagnóstico definitivo relacionado ao motivo de encaminhamento e as conclusões principais foram: 1) alta incidência de normalidade foi encontrada: sopro (83\%), dor precordial (98\%), arritmia (97\%) e dispnéia $(94 \%) ; 2$ ) a presença de cardiopatia foi considerada improvável baseado nos outros motivos de encaminhamento; 3 ) $14 \%$ das crianças foram consideradas anormais e a necessidade de procedimento terapêutico invasivo foi de $1 \%$ dos casos. Conclusões: 0 estabelecimento de um ambulatório de cardiologia pediátrica na rede pública de saúde parece ser justificado na região devido à alta demanda encontrada. A baixa incidência global de cardiopatia, com número expressivo de crianças com sopro inocente, sugerem a necessidade de um programa específico de treinamento básico em cardiologia pediátrica para pediatras. 